\title{
Próteses auditivas por idosos: aspectos psicossociais, adaptação e qualidade de vida
}

\author{
Hearing prostheses for elderly: psychosocial features, adaptation \\ and quality of life
}

\section{Entendre prothèses pour personnes âgées: aspects psychosociaux, adaptation et qualité de vie}

Prótesis auditivas para ancianos:aspectos psicosociales, adaptación y calidad de vida

\author{
Regiane Bergamo Gomes da Silva* \\ (regianebergamo@gmail.com) \\ Luciane Pinho de Almeida* \\ (luciane@ucdb.br)
}

Recebido em 13/12/2015; revisado e aprovado em 25/02/2016; aceito em 25/04/2016 DOI: http://dx.doi.org/10.20435/1984-042X-2016-v.17-n.3(09)

\begin{abstract}
Resumo: Este trabalho teve como objetivo compreender os aspectos psicossociais decorrentes do uso de próteses auditivas para idosos e a forma como estas contribuem para a melhoria da qualidade de vida dessa população. Foi realizado um estudo qualitativo com 05 idosos, utilizando a entrevista não estruturada. Os resultados apontam a melhora na qualidade de vida dos idosos após a adaptação da prótese auditiva, porém é um processo contínuo, pois os aspectos psicossociais que influenciam seu uso incidem diretamente na sua relação com o outro.
\end{abstract}

Palavras-chave: idosos; próteses auditivas; qualidade de vida.

Abstract: This work aims at understanding the psychosocial features resulting from the use of hearing prostheses by elderly and how this device has improved their quality of life. The author made a qualitative study by analysing five elderly, using as a method of work non-structured interviews. The results show a significant improvement of their quality of life after being used to the hearing device. This adaptation is a continuous process, in the sense that psycosocial features have a strong impact on their relationships.

Key words: elderly; hearing prostheses; quality of life.

Résumé: Ce travail a eu pour but comprendre les aspects psychosociaux de l'usage des entendre prothèses par des personnes âgées et comme ses instruments ont amélioré leurs qualité de vie. L'auteur a fait un étude qualitatif en étudiant le comportement de cinq personnes âgées en utilisant la méthode des interviews non-structurés. Les résultats démontrent une significatif amélioration de leurs qualité de vie après avoir fait usage de l'appareil. L'adaptation est un processus continue à la mesure que se produit un profond impact sur leurs relations personnelles.

Mots clés: personnes âgées; entendre prothèses; qualité de vie.

Resumen: Este trabajo tiene por propósito comprender los aspectos psicosociales resultantes del uso de prótesis auditivas por ancianos y como ese cambio afecta la calidad de vida de los examinados. Fue hecho un estudio cualitativo con base en cinco ancianos, utilizando como método de trabajo entrevistas no estructuradas. Los resultados apuntan para la mejora de la calidad de vida de los ancianos después que se produzco la adaptación al aparato. Esa adaptación es un proceso continuo, pues los aspectos psicosociales que influencian su uso tienen fuerte impacto en las relaciones personales.

Palavras claves: ancianos, prótesis auditivas; calidad de vida.

\footnotetext{
* Universidade Católica Dom Bosco (UCDB), Campo Grande, Mato Grosso do Sul, Brasil.
} 


\section{INTRODUÇÃO}

Vários fatores que influenciam na decisão do uso de próteses auditivas por idosos e os aspectos psicossociais envolvidos nessa questão têm chamado a atenção de pesquisadores da área, com o intuito de entender como tais aspectos poderiam interferir nesse processo e contribuir para um envelhecimento bem sucedido.

Freire (2000) relata que com o entendimento de que a velhice não significa necessariamente doença, e sendo o idoso capaz de mudanças, o significado de envelhecimento bem sucedido passa a ter maior importância, considerando o grande número de pessoas que espera gozar de uma longa velhice. Existe hoje uma maior consciência de que os idosos podem sentir-se felizes e realizados e de que, quanto mais atuantes e integrados em seu meio social, menos ônus trarão para a família e para os serviços de saúde. Assim, experienciar a velhice passa a ser cada vez menos uma possibilidade para se tornar uma certeza e o que se busca são ferramentas para continuar vivendo com qualidade.

Rigo e Teixeira (2005), Russo, Almeida e Freire (2003) e Tesch-Römer (1997) consideram que essa etapa da vida pode vir acompanhada de perdas psicossociais como isolamento, depressão, frustração, irritabilidade e sentimento de solidão, além de consequências biológicas, dentre as quais se citam alterações na saúde geral, problemas de destreza manual, deficiência visual e deficiência auditiva.

Hull (1999) destaca que um dos mais frustrantes déficits sensoriais que acompanham o processo de envelhecimento é a deterioração da função auditiva, conhecida como presbiacusia, que pode ser definida como uma desordem auditiva multidimensional que afeta cerca de $40 \%$ de todas as pessoas com idade acima de 65 anos. Desse modo, o impacto da deficiência auditiva é relevante, pois leva a alterações significativas nas capacidades comunicativas do sujeito, que em função delas, deixa de participar das atividades sociais e familiares.

Entretanto a maioria dos pacientes idosos com perda auditiva pode ser reabilitada e esse procedimento pode apresentar bons resultados. Megale (2006) destaca em seu estudo que, para minimizar os efeitos decorrentes dessas dificuldades, os idosos podem se beneficiar do uso da prótese auditiva, também conhecida como Aparelho de Amplificação Sonora Individual (AASI) ou equipamento auxiliar para audição. Contudo sabe-se que, apesar do avanço tecnológico, as próteses auditivas não conseguem ser um substituto da orelha, mas algo importante, que se tornou um grande aliado para os deficientes auditivos em busca de um aprimoramento da comunicação, sempre que não seja possível algum outro tratamento.

A pesquisa que originou este artigo teve por objetivo compreender os aspectos psicossociais decorrentes do uso de próteses auditivas por idosos e a forma como contribuem para a melhoria da qualidade de vida dessa população. Para tanto, optou-se pela abordagem qualitativa, a partir dos relatos dos participantes da pesquisa.

Vários estudos já foram realizados na tentativa de se compreender como os aspectos psicossociais da perda auditiva e do uso de próteses auditivas influenciam na qualidade de vida dos idosos. Entretanto, em sua grande maioria, observa-se que estas foram realizadas de forma quantitativa, através de escalas e questionários fechados. Por esse motivo, entendeu-se ser de grande relevância a realização de uma pesquisa qualitativa, pois esta permite melhor compreensão das questões subjetivas pertinentes aos participantes da pesquisa, desvendando particularidades difíceis de serem identificadas em pesquisas quantitativas.

No contexto de saúde, melhorar a qualidade de vida dos pacientes é um dos principais objetivos a serem alcançadose, 
no caso dos idosos com perda auditiva, o uso de próteses auditivas apresenta-se como a melhor forma de intervenção na busca da qualidade de vida. No entanto é fundamental que a opinião e os valores dos envolvidos sejam considerados, dedicando-se lugar privilegiado à compreensão do indivíduo e às formas que ele utiliza para interpretar suas vivências.

Nesse sentido, buscou-se analisar e compreender as expectativas e impactos ocorridos na vida de idosos com perda auditiva que optaram pelo uso de próteses auditivas, o que possibilitou descrever e explicar a realidade estudada.

Para atingir o objetivo previamente planejado, foram entrevistados cinco idosos com idades entre 62 e 75 anos, de ambos os sexos, sendo três homens e duas mulheres, que passaram pelo processo de diagnóstico da deficiência auditiva e apresentavam a devida indicação médica para o uso de prótese auditiva.

Segundo Minayo (2007), a entrevista é considerada uma conversa a dois, uma forma privilegiada de interação social e tem por objetivo construir informações importantes para um objeto de pesquisa. Dessa forma, os dados foram construídos por meio da realização de entrevistas não estruturadas, com o objetivo de investigar através de relatos orais dos participantes suas explicações sobre os assuntos em questão.

Para a análise dos dados foi realizada a leitura das falas obtidas nas entrevistas, para apreensão global das ideias, informações e seus significados. Os dados foram organizados e agrupados conforme o conteúdo apresentado em cada pergunta, para identificação dos temas e dos subtemas.

Após a organização dos dados, foi possível explorar o material, fase que representa a administração sistemática da análise de dados da pesquisa, visando alcançar o núcleo de compreensão do texto. Emergiram temas e subtemas a partir do contexto das falas dos participantes da pesquisa, considerando-se a frequência e a relevância a determinado assunto.

A partir do processo de organização dos dados, foi realizado o tratamento dos resultados obtidos e sua interpretação. Os dados construídos através das entrevistas não estruturadas junto aos participantes foram submetidos a análises que permitiram destacar as informações encontradas, bem como as inferências para esclarecer as descobertas da pesquisa. Sendo assim, a análise foi realizada de acordo com os seguintes passos: transcrições das entrevistas, criação de uma estrutura de temas, identificação e classificação dos relatos obtidos segundo o tema ao qual se referiam e elaboração de subtemas a partir da descrição do assunto e análise propriamente dita.

Diante dessa realidade e considerando que a inabilidade de comunicação em função da deficiência auditiva pode resultar em significativos problemas psicossociais, este estudo teve como resultados a apreensão de uma visão geral a respeito da construção social da velhice e do impacto da prótese auditiva na qualidade de vida de indivíduos com idade de 60 anos ou mais.

\section{AS CONSEQUÊNCIAS PSICOSSO- CIAIS DA DEFICIÊNCIA AUDITIVA NO IDOSO}

Além de ser considerado externo à pessoa, o envelhecimento não é bem-vindo em nossa cultura e sociedade. A diminuição das funções físicas no idoso, como agilidade e coordenação motora, torna-se ainda mais complicada com as falhas na visão e na audição. Como resultado, o indivíduo idoso sente que perdeu seu lugar na sociedade, na família e no trabalho (ROSENHALL, 2002).

Mas o que mais se evidencia no processo de envelhecimento são as alterações da comunicação, especialmente aquelas causadas pela perda de audição. As dificuldades causadas pela diminuição 
da audição marginalizam ainda mais o idoso, levando-o a uma vida menos ativa, mais isolada e comprometem as condições físicas e psíquicas, não só pela redução das atividades físicas e intelectuais que esse fato gera, mas também pela solidão, ansiedade e desgaste da imagem pessoal (CHEN, 1994).

Para Signorini (1989), a deficiência auditiva pode ter implicações no relacionamento social do idoso por limitar a sua interação comunicativa. Muitos até, por não se sentirem à vontade para pedir que repitam a conversa, deixam de frequentar lugares movimentados como teatro, cinema, restaurante, reuniões familiares e começam a se afastar do seu convívio social.

No caso dos idosos, esses problemas são potencializados, já que se transformam em mais um fator de desagregação social. O declínio do status desses idosos na sociedade e na família tende a isolá-lo e privá-lo de fontes de informação e comunicação, levando-os a um profundo impacto social. Para os idosos, muitas vezes, acaba sendo mais cômodo afastar-se das situações de interação do que enfrentar os constrangimentos decorrentes da falta de compreensão (RUSSO, 1999).

Os conflitos gerados no ambiente familiar em decorrência das dificuldades de comunicação apresentadas por esses indivíduos podem levá-los ao isolamento e à depressão. Muitas vezes o deficiente auditivo acredita que não há um esforço da família para propiciar uma comunicação efetiva. Em contrapartida, é comum os familiares alegarem que o deficiente auditivo só escuta quando quer (IERVOLINO; CASTIGLIONE; ALMEIDA, 2003).

Russo (2004, p. 586) destaca o fator psicossocial da deficiência auditiva e descreve que:

[...] de todas as privações sensoriais, a perda auditiva é a que produz efeito mais devastador no processo de comunicação do idoso. A deficiência auditiva é uma das condições mais incapacitan- tes: limita a ação de seu portador ou o impede de desempenhar seu papel na sociedade de maneira plena. Além disso, tem sérias implicações psicossociais em sua qualidade de vida e na qualidade de vida daqueles que convivem com ele no dia a dia.

Como se observa, a deficiência auditiva pode trazer consequências ruins para essa população, pois os conflitos e as dificuldades geradas por ela ao idoso são acentuados e se transformam em mais um fator de desagregação social. Entretanto a maioria dos indivíduos com presbiacusia pode ser reabilitada através de uma intervenção adequada, como o uso das próteses auditivas, apresentando bons resultados.

\section{PRÓTESES AUDITIVAS: RELAÇÃO DE DESEMPENHO E SUAS IMPLICAÇÕES PSICOSSOCIAIS}

Um dos maiores desafios no processo de reabilitação auditiva nos idosos é a seleção, indicação e avaliação da prótese auditiva, pois ela se constitui um instrumento fundamental nesse processo. A efetividade das próteses auditivas melhorou de forma considerável nos últimos anos. Atualmente, são equipamentos individualizados, miniaturizados, digitais ou digitalmente programáveis, versáteis e dotados de controles, os quais são de fácil manipulação por qualquer indivíduo, até mesmo por aqueles mais idosos. Além disso, facilitam a recepção do sinal de fala, promovendo melhor contato social e autoconceito mais positivo (ALMEIDA; RUSSO, 1995).

\subsection{A prótese auditiva como um recurso tecnológico benéfico}

Em função do impacto da deficiência auditiva na vida psicossocial dos idosos, a possibilidade de usar próteses auditivas, minimizando sua perda auditiva e 
facilitando sua comunicação, pode ter um sentido de motivação e ser significativa para a melhoria da sua qualidade de vida (GIL, 2006).

Durante as entrevistas, foi possível observar que os participantes associaram a decisão de se usar a prótese auditiva como um mecanismo alternativo para melhorar a comunicação e de certa forma sair do isolamento.

$P 1^{1}$ : "Usar o aparelho é muito, mas muito bom mesmo, porque ele me aproxima das pessoas, mesmo sendo uma coisa que eu tenho que me acostumar, ele me ajuda a ouvir, não é mesmo? E quer coisa melhor que poder conversar com os amigos?"

P 4: "Eu acho que o aparelho é uma coisa muito boa, que ajuda a gente né? Por exemplo, antes eu não conseguia entender nada e agora escuto bem, ouço bem quando a pessoa fala comigo. Olha aí você falando, perfeito, tô te ouvindo bem, certo?"

Pelos relatos acima, pode-se perceber que, para essas pessoas, as próteses auditivas se mostraram extremamente úteis e eficazes nas situações do cotidiano, proporcionando-lhes maior independência e interação social. Dentre esses segmentos discursivos, os participantes enfatizaram haver uma melhora quanto à qualidade sonora, uma vez que esses equipamentos favorecem a compreensão da fala e com eles é possível ouvir com mais clareza o que é dito. Isso trouxe consequências diretas nas relações sociais nas quais estão inseridos e, assim, em sua qualidade de vida.

\subsection{O reconhecimento das limitações da prótese auditiva}

Apesar do claro sentido positivo do uso das próteses auditivas por idosos, os

\footnotetext{
$\overline{{ }^{1} \text { A siglas } \mathrm{P} 1-\mathrm{P} 2}$ - P3 - P4 - P5 indicam o paciente participante da pesquisa e resguardam a sua real identidade.
}

participantes atribuíram sentidos negativos quanto ao seu uso, uma vez que perceberam que esses equipamentos não são capazes de solucionar todos os problemas decorrentes da deficiência auditiva, sendo que as principais queixas se referem à dificuldade de compreensão em situações em que há vários interlocutores.

Sendo assim, observou-se que, mesmo fazendo uso das próteses auditivas e percebendo seus benefícios, os participantes ainda têm queixas em relação ao desempenho desssas próteses em determinadas situações. Entretanto, diante dos relatos, o que se destaca é que os benefícios superam as limitações, o que pode ser observado nos trechos em que situações ressaltando um aspecto negativo ou de certa limitação da prótese são seguidas de algum comentário reconhecendo os seus benefícios.

P 1: "Minha vida mudou cem por cento. É muito bom ouvir as pessoas... Ah só tem outra coisa, quando tem muita gente falando complica."

P 2: "Agora eu escuto mais né? É uma coisa muito boa. Só que mesmo com os aparelhos, eu não entendo muito bem as palavras quando tem muita gente junta. Lá em casa, quando tá todo mundo, os filho, neto, os parente, eles falam tudo junto e eu fico ainda perdida."

As falas registram o benefício trazido pelo uso das próteses auditivas em situações de conversas com familiares e outras pessoas, mas podemos perceber ainda as queixas referentes à dificuldade de compreensão em situações em que há vários interlocutores.

\subsection{A atitude de resignação e o autocuidado}

Podemos observar que os participantes se colocam discursivamente no lugar de alguém que "aceita as dificuldades" com resignação, sem se revoltar com a situação. Diferentemente dos outros 
relatos, este não se restringe apenas ao uso das próteses auditivas, mas se refere também à maneira como se posicionam na vida. Entretanto a atitude de resignação dos participantes parece ser vista como um fator de facilitação do processo de adaptação das próteses.

P 1: "É... ontem, por exemplo, eu tava na casa de uma amiga minha, fui lá tomar um café com ela, ela falou vamos assistir "Chocolate com Pimenta", ai eu aumenta um pouquinho, aumenta um pouquinho, aí ela olhou pra mim e falou põe o aparelho, eu falei ah é o aparelho. Aí eu peguei, já saindo do treino fui pra lá então eu tava sem aparelho. Botei o aparelho não precisou aumentar mais a televisão. Aí que eu vejo o quanto fico surda sem os aparelhos e o quanto eles me ajudam."

P 4: "Até esqueço que estou de aparelho, outro dia entrei no chuveiro e quando vi estava com os aparelhos (risos) e corri tirar. Mas é bom mesmo, maravilhoso. E a gente se acostuma né? Se é bom, se está fazendo a gente ouvir melhor, então tem que usar né?"

Essa realidade evidencia, nos relatos dos participantes, que estes buscam fazer reflexões que demostram que o uso da prótese auditiva não é tão complicado assim. Para fundamentar essas reflexões, argumentam que já passaram por processo de adaptação semelhante e que estão bem, e que o uso da prótese é algo que vem a somar a tantas coisas positivas que possui em sua vida. Demonstram ainda que conseguem compreender e aceitar as dificuldades sem se revoltar, mostrando-se capazes de refletir sobre as adversidades e superá-las pacificamente.

\subsection{A busca pelo tratamento: a pressão imposta pela família e pela sociedade}

Lutfi (2006) refere que grande parte dos participantes de seu estudo teve a deficiência auditiva descoberta por algum membro da família ou amigos em função das críticas ou discussões geradas pelas dificuldades auditivas.

Emergiram, por parte dos participantes, sentidos que relacionavam a deficiência auditiva e o uso da prótese auditiva ao modo como estas afetam os outros e a eles próprios. Esses sentidos se referiram à falta de compreensão do problema por parte das pessoas de seu convívio em relação às dificuldades comunicativas apresentadas, bem como às próprias reações frente a tais dificuldades e à pressão social imposta para o uso da prótese auditiva.

\section{P 1: "Aqui em Campo Grande eu voltei a perceber, ou melhor, pessoas perceberam, uma prima minha notou que... ela falou porque que quando a gente conversa você fica virando a cabeça, acho que você não está escu- tando direito, falei é verdade, quando você fala deste lado eu não escuto. Aí ela sugeriu que eu procurasse um médico, pois como a mamãe também era surda, poderia ser hereditário. Aí eu procurei e agora estou muito melhor."}

P 3: "Meu fio sempre ficava cobrando de eu ir buscar ajuda com aparelho, que o governo dava de graça. Porque eu sempre colocava a televisão muito alto, né? E ele ficava nervoso. Aí eu procurei. E agora tô melhor, ouvindo melhor, né? A família ficou mais contente."

O que podemos observar nos relatos é que existe a pressão social para que a busca pela prótese auditiva seja concretizada, pois as dificuldades comunicativas decorrentes da perda de audição afetam não somente a vida da pessoa deficiente auditiva, mas também dos familiares e daqueles que fazem parte do seu meio, dificultando o relacionamento social. 


\section{A PRÓTESE AUDITIVA COMO INS- TRUMENTO DE INCLUSÃO SOCIAL E SEU IMPACTO NA QUALIDADE DE VIDA DOS IDOSOS}

O conceito de inclusão não nega o conceito de desigualdade, na verdade defende o convívio dos desiguais de maneira igualitária. É por existirem as desigualdades que o ser humano busca o convívio com iguais e procura se associar a vários grupos (BATISTA, 2000).

Para Sassaki (1997) a inclusão é o processo pelo qual a sociedade se adapta para poder incluir em seus sistemas sociais gerais pessoas com deficiência e, simultaneamente, estas se preparam para assumir seus papéis na sociedade.

Um mundo inclusivo é, portanto, um mundo no qual todas as pessoas têm acesso às oportunidades de ser e estar na sociedade. Assim se, por um lado, a exclusão pode ser entendida como um descompromisso político com o sofrimento, do outro (SAWAIA, 1999), a inclusão significa humanizar caminhos (WERNECK, 1997).

Entretanto, ainda que fosse reconhecido o mérito da integração social em promover a inserção do deficiente na sociedade, nas duas últimas décadas surgiram novos questionamentos quanto a essa proposta, provenientes da academia e das próprias pessoas com deficiência e suas famílias. Elas apontavam as reais dificuldades encontradas no processo da normalização da pessoa com deficiência, uma vez que as diferenças, na realidade, não se apagam, mas devem ser administradas na convivência social (ARANHA, 2001).

Vários estudos já expostos neste trabalho foram realizados com o intuito de investigar o benefício do uso de próteses auditivas por idosos e a sua relação com a melhora na qualidade de vida dessa população. Tais estudos demonstram uma relação positiva tanto do benefício quanto da melhora na qualidade de vida dos idosos usuários de próteses e, conse- quentemente, da inclusão social desses indivíduos.

Com o diagnóstico da deficiência auditiva e, consequentemente, com as limitações físicas, sociais e psicológicas que ela acarreta e que, após a adaptação da prótese auditiva serão amenizadas, observa-se nos relatos uma reflexão subjetiva e particular sobre o viver com qualidade de vida. Assim, dentre os relatos, destacaram-se: Relações interpessoais - família/amigos, convívio social e comunicação.

A deficiência auditiva acarreta mudanças nas relações interpessoais, sendo o ambiente familiar o local mais frequente para as adaptações, tornando importante o esclarecimento de suas consequências, para promover o domínio da situação e, com isso, diminuir o seu impacto na vida do sujeito idoso e, por conseguinte,evitar o seu isolamento e exclusão social.

Os relatos dos participantes apontam que a qualidade de vida depende de boas relações familiares e sociais:

P 1: "Para mim, qualidade de vidaé, em primeiro lugar ter saúde, é estar bem, se sentir bem, viver bem com as pessoas."

P 4: "Eu, por exemplo, acho que tenho uma ótima qualidade vida, estou com saúde, tenho uma boa convivência com a família, os filhos, né? E agora com esse aparelho auditivo ficou melhor ainda."

Esses relatos vêm ao encontro do conceito de qualidade de vida sugerido por Wilheim (1978 apud CORREAA; TOURINHO, 2001), que chama a atenção para a garantia de condições de conforto e satisfação psicológica, física e familiar dos indivíduos, devendo ainda ser entendido como a sensação de bem-estar de cada um, sendo que esta depende tanto de fatores materiais quanto de aspectos subjetivos.

A vida social e familiar de pacientes idosos usuários de prótese auditiva passa por uma adaptação considerada complexa. 


\begin{abstract}
A família é o primeiro grupo em que o indivíduo participa, é nela que temos a oportunidade de vivenciar diferentes experiências, sendo elas positivas (afeto, carinho, estímulo, apoio, respeito) ou negativas (frustrações, limites, tristezas, perdas), e esse fato irá influenciar na formação da pessoa futuramente. (OLIVEIRA, 2011apud LANZARINI et al., 2013.
\end{abstract}

Delgado (1997) acrescenta ainda que a família é considerada como a primeira instituição social de qualquer ser, tendo papel fundamental para o desenvolvimento do indivíduo. Dessa forma, com o aconselhamento não só do usuário da prótese auditiva, mas também dos familiares, é possível fornecer instrumentos para que possa haver maior aceitação do problema, uma atitude positiva frente às dificuldades de comunicação enfrentadas e, por fim, motivação no que diz respeito ao uso efetivo das próteses auditivas. As pessoas que convivem com o usuário de prótese auditiva necessitam conhecer as limitações da perda de audição e das próteses, bem como os meios adequados para compensá-las por meio de ajustes do ouvinte e do falante às estratégias de comunicação (GATES; MILLS, 2005; MUSIEK; LEE, 2001).

Sendo assim, é fundamental a participação efetiva da família para o sucesso da reabilitação, fazendo com que os transtornos psicossociais ocasionados pela deficiência auditiva sejam superados ou minimizados, refletindo na melhora da qualidade de vida do idoso.

No contexto da qualidade de vida, o convívio social é fundamental para os participantes, no qual estes demonstraram que, para ter qualidade de vida, é necessário também viver em sociedade.

Murlow et al. (1990) realizaram um estudo no qual observaram melhora das funções social, emocional, comunicativa e cognitiva, além da diminuição da depres- são em indivíduos usuários de próteses auditivas, quando comparados aos que aguardavam em uma fila de espera para receber as próteses.

Lutfi (2006) refere que essa melhora no relacionamento social proporcionada pelo uso das próteses auditivas merece destaque, uma vez que isso seria o grande objetivo desses equipamentos. Popelka et al. (1998) ressaltam ainda que, em função da melhora do relacionamento social, as próteses auditivas atenuam uma das consequências mais sérias da deficiência auditiva, o isolamento social. Sendo assim, as próteses adquiriam o sentido de instrumentos que possibilitam e favorecem o contato com o mundo, devolvendo aos deficientes auditivos o convívio com as pessoas e interação com o meio.

P 1: "Agora consigo participar
das conversas sem ter que ficar
perguntando ou pedindo para
repetir toda hora. É claro que tem
coisa que a gente perde da conversa,
mas é pouco, é mais quando tem
muita gente falando ao mesmo tempo.
Mas a sensação de ouvir e enten-
der o que as pessoas falam, ah
isso é muito bom. Outro dia, saí do
vôlei e passei no posto para abastecer
o carro e como eu estava suada, aí
não ia colocar os aparelhos né, eu não
conseguia entender o que o rapaz do
posto falava e ficava hã hã hã (risos),
muito ruim ficar sem ele".

$P$ 3: "Hoje eu converso com todo mundo. É bom a gente num tê que fica perguntando toda hora. O mesmo causo na igreja, antes virava uma baruiera só (risos) num intendia era nada. Agora já tá bom, mas tem que fica longe da caixa de som, senão é... aí atrapaia di entendê."

P 4: "Como te falei, na sala de aula agora fico tranquilo. Não preciso sentar tão na frente, já mais atrás escuto muito bem, mesmo com as pessoas conversando, consigo en- 
tender muito bem. Até esqueço que estou de aparelho, outro dia entrei no chuveiro e quando vi estava com os aparelhos (risos) e corri tirar. Mas é bom mesmo, maravilhoso."

P 5: "Quando vou na vendinha perto de casa agora é... vou lá e converso bem, quando os moço fala agora eu entendo o que tão falando. É mais fácil assim, a gente num fica constrangido."

Segundo Assayag e Russo (2006), existem diferenças estatisticamente significantes na avaliação subjetiva do benefício percebido por idosos quando comparadas às situações com e sem próteses auditivas, sendo que o benefício era mais bem percebido quando o indivíduo utilizava as próteses.

Chisolm et al. (2007) conduziram uma revisão de literatura sistemática através de uma meta-análise com o objetivo de buscar evidências no que diz respeito à relação entre o uso de próteses auditivas e a melhora na qualidade de vida de adultos com perda auditiva neurossensorial. Dos 171 resumos considerados relevantes e encontrados na pesquisa inicial, os autores destacaram 16 artigos que obedeciam a todos os critérios de inclusão pré-determinados no estudo. A revisão concluiu que o uso das próteses auditivas melhora a qualidade de vida dos adultos, reduzindo os efeitos psicológicos, sociais e emocionais decorrentes da perda auditiva neurossensorial.

É possível identificar nos depoimentos colhidos que a maioria dos participantes, usuários de próteses auditivas de forma efetiva, percebeu melhorias significativas em sua qualidade de vida. Esse benefício é observado nas seguintes situações: em conversas com familiares e com estranhos, em reuniões da comunidade, na igreja, para assistir televisão, entre outras situações do seu cotidiano.

P 1: "É, sem duvida... Minha vida mudou cem por cento. É muito bom ouvir as pessoas. É muito bom poder encontrar com os amigos em reuniões e poder conversar. Agora, quando vou na casa de algum amigo, sento e converso, todo mundo conversa comigo porque vê que estou de aparelho."

P 2: "Ah como minha vida melhorou. Acho que tenho mais qualidade de vida sabe, porque agora nos aniversário em família participo, $e$ isso é social né? É muita alegria ver que agora eu entendo e participo das conversa."

P 5: "Ah vixi, melhorou muito, né? A família percebeu, ninguém fica mais reclamando. Agora eu ainda tenho alguma dificuldade sim, mas consigo conversar e participo dos assunto, né? Eu tava me sentindo fora do mundo. Agora não."

As falas revelam que o uso da prótese auditiva diminui o isolamento dos idosos e aumenta a autonomia nas atividades que envolvem o contato com o outro, uma vez que se sentem mais seguros em situações de comunicação, com repercussão positiva nas relações sociais.

Em relação à comunicação, os relatos apontam que todos os participantes atribuíram sentidos positivos ao uso das próteses. Esses sentidos foram relacionados à melhora nas situações de comunicação, na audibilidade dos sons e compreensão da fala e à satisfação pelos benefícios proporcionados com o seu uso.

P 1: “Eu não fico mais hã hã hã... Escuto o que falam numa roda de amigos, é claro que eu fico mais perto né, procuro prestar mais atenção em quem está falando, mas eu escuto. E em casa escuto bem agora, a televisão não precisa ficar com volume alto $\boldsymbol{e}$ nem as pessoas precisam mais gritar comigo."

$P$ 2: "Ah tudo melhorou né. Levantou a estima, a gente se sente melhor, porque escuta as pessoas. 
Assim, antes ficava retraída, porque não escutava as conversa. Então eu acho que foi muito bom. Quando o marido fala, agora, eu num fico mais perguntando toda hora, é claro que ele também tem que falar mais perto né, mas melhorou muito. E quando os filho tão em casa, os neto, é uma bagunça, uma barulheira (risos) mas mesmo assim eu consigo conversar. É bom mesmo."

P 5: “É uma coisa que é muito boa né, porque a gente escuta mais, quando tem bastante gente escuta melhor e participa né. A família também vê que melhorou e num precisa mais assim falar tão alto com a gente, a gente fica até mais feliz pra ir passear, na casa dos parente, dos amigo. Uma coisa boa mesmo."

Pelos relatos acima, percebe-se que, para estas pessoas, as próteses auditivas se mostraram extremamente úteis e eficazes nas situações do cotidiano, proporcionando-lhes maior independência e interação social. Dentre esses segmentos discursivos, os participantes enfatizaram haver uma melhora quanto à qualidade sonora, uma vez que esses equipamentos favorecem a compreensão da fala e com eles é possível ouvir com mais clareza o que é dito. Isso trouxe consequências diretas nas relações sociais nas quais estão inseridos e, assim, em sua qualidade de vida.

Mas, mesmo sabendo dos benefícios que podem ser obtidos com o uso das próteses auditivas, muitos idosos ainda optam por não utilizá-las. Kochkin (2003) chama a atenção para os resultados das pesquisas que demonstram que, mesmo havendo uma grande ocorrência de perda auditiva na população idosa, apenas cerca de $20 \%$ dos indivíduos idosos com perda de audição significativa adquirem próteses auditivas. Além disso, cerca de $30 \%$ dos usuários estão insatisfeitos com suas próteses e aproximadamente 16\% dos usuários relatam nunca terem usado de forma efetiva suas próteses.
Assim, considera-se que o acompanhamento em todo processo de adaptação da prótese auditiva é fundamental, pois o profissional pode, junt com o paciente idoso, compreender as suas dificuldades e buscar soluções, proporcionando melhora na adaptação e na qualidade de vida dessa população.

\section{CONSIDERAÇÕES FINAIS}

Este estudo propiciou várias reflexões que contribuíram para um melhor entendimento das vivências, percepções e expectativas do idoso em relação à perda de audição, dentro da complexidade dos temas próteses auditivas e qualidade de vida.

Os dados desta pesquisa demonstram que a perda auditiva afeta a qualidade de vida dos idosos, uma vez que a falta de interação com o meio em que vivem e também com a sociedade favorece o isolamento comunicativo e a consequente privação social.

As mudanças decorrentes do uso das próteses auditivas apresentam-se de forma positiva, como a melhora das funções social, emocional e comunicativa, que eram marcantes no contexto da deficiência auditiva e que eram restritas antes da adaptação desses equipamentos. Os participantes concordam que houve melhora nessas condições, propiciando encorajamento e bem-estar.

A partir das reflexões geradas por este trabalho, o que observamos até aqui é que os sentidos são produzidos durante as inter-relações humanas. Dessa forma, a maneira como nos relacionamos com os idosos deficientes auditivos poderá interferir na forma como eles irão dar sentido ao uso das próteses auditivas. Por isso, devemos ter o compromisso de ouvir o sujeito de forma cuidadosa e abrangente, buscando, durante nossas inter-relações, a produção de sentidos que possam auxiliar o idoso no seu processo de reabilitação audiológica. 
Concluiu-se, através dos depoimentos dos participantes, que a prótese auditiva contribuiu na melhora da qualidade de vida dos idosos, não deixando de enfatizar as limitações apresentadas por ela. Dessa forma, espera-se que as reflexões aqui geradas possam vir a se somar ao universo de estudos já realizados sobre o assunto permitindo, assim, a construção de novas pesquisas sobre a temática, as quais poderão auxiliar no aperfeiçoamento do atendimento a essa população.

\section{REFERÊNCIAS}

ALMEIDA, Kátia; RUSSO, Ieda C. P. O processo de reabilitação audiológica do deficiente auditivo idoso. In: MARCHESAN, Irene (Org.). Tópicos em fonoaudiologia. São Paulo: Lovise, 1995.

ARANHA, M. S. F. Paradigmas da relação da sociedade com as pessoas com deficiência. Revista do Ministério Público do Trabalho, ano XI, n. 21, p. 160-173, 2001. Disponível em: <http:// www.centroruibianchi.sp.gov.br/usr/share/ documents/08dez08_ biblioAcademico_ paradigmas.pdf>. Acesso em: 20 sete. 2013.

ASSAYAG, F. H. M.; RUSSO, I. C. P. Avaliação subjetiva do benefício e dos efeitos proporcionados pelo uso de amplificação sonora em indivíduos idosos. Distúrbios da Comunicação, v. 18, n. 3, p. 383-390, 2006.

BATISTA, C. A. M. et al. Inclusão dá trabalho. Belo Horizonte, MG: Armazém de Ideias, 2000.

CHEN, H. L. Hearing in the elderly . Relation of hearing loss, loneliness, and self-estem. J. Gerontology Nurs, v. 20, n. 6, p. 22-28, jun. 1994.

CHISOLM, T. H. et al. A Systematic review of health related quality of life and hearing aids: final report of the American Academy of Audiology task force on the health related quality of life benefits of amplification in adults. Journal of the American Academy of Audiology, v. 18, n. 2, 2007.

CORRÊA, A. J. L.; TOURINHO, H. L. Z. Qualidade de vida urbana na Amazônia: os casos de Marapanim e Vila dos Cabanos. Belém, PA: UNAMA, 2001. (Série Relatórios de Pesquisas).
DELGADO, A. R. A importância da integração da família no processo terapêutico: relato de experiência em clinica escola. In: LAGROTTA, M. G. M.; CÉSAR, C. R. H. A. R. (Org.). A fonoaudiologia nas instituições. São Paulo: Lovise, 1997.

FREIRE, S. A. Envelhecimento bem sucedido e bem-estar psicológico. In: NERI, A. L.; FREIRE, S. A. (Org.). E por falar em boa velhice. Campinas, SP: Papirus, 2000. p. 21-31.

GATES, G. A.; MILLS , J. H . Presbycusis. Lancet: Review, 2005.

GIL, D. Treinamento auditivo formal em adultos com deficiência auditiva. 2006. Dissertação (Mestrado em Fonoaudiologia) - Universidade Federal de São Paulo, São Paulo. Disponível em: <http://www.bdtd.unifesp.br/tede// tde_busca/arquivo.php? codArquivo=52>. Acesso em: 15 abr. 2013.

HULL, R. H. Atendimento ao paciente idoso. In: KATZ, J. (Org.). Tratado de audiologia clínica. São Paulo: Manole, 1999. p. 783-792.

IERVOLINO, S. M. S.; CASTIGLIONI, M.; ALMEIDA, K. A orientação e o aconselhamento no processo de reabilitação auditiva. In: ALMEIDA, K.; IORIO, M. C. M. I. (Org.). Próteses auditivas: fundamentos \& aplicações clínicas. São Paulo: Lovise, 2003. p. 411-427.

KOCHKIN, S. Marke Trake VI: On the issue of value: hearing aid benefit, price, satisfaction and brand repurchase rates. Hearing Review, v. 10, n. 2, 2003.

LANZARINI, Ivanilde de Fátima et al. A percepção dos familiares de usuários de próteses auditivas em relação à perda auditiva e suas limitações. Tuiuti: Ciência e Cultura, Curitiba, n. 46, p. 117-127, 2013.

LUTFI, A. Deficiência auditiva em idosos: relatos orais sobre o impacto proporcionado pelo uso de aparelho de amplificação sonora. 2006. Dissertação (Mestrado em Fonoaudiologia) - Pontifícia Universidade Católica de São Paulo, São Paulo.

MEGALE, R. L. Treinamento auditivo: avaliação do benefício em idosos usuários de próteses auditivas. 2006. 154 f. Dissertação (Mestrado em Ciências) - Faculdade de Medicina, Universidade de São Paulo, São Paulo. 
MINAYO, M. C. S. O desafio da pesquisa social. In: MINAYO, M. C. S. (Org.). Pesquisa social: teoria, método e criatividade. 25. ed. Petrópolis, RJ: Vozes, 2007. p. 9-29.

MURLOW, C. D. et al. Quality of life changes and hearing impairment. Annals of Internal Medicine, v. 113, n. 3, p. 188-194, 1990.

MUSIEK, F. E.; LEE, W. W. Reabilitação auditiva do idoso. In: MUSIEK, F. E.; RINTELMANN, W. F (Org.). Perspectivas atuais em avaliação auditiva. Barueri, SP: Manole, 2001.

POPELKA. M. M. et al. Low prevalence of hearing aid use among older adults with hearing loss: the epidemiology of hearing loss study. American Geriatrics Society, v. 16, n. 9, 1998.

RIGO, M. L. N.; TEIXEIRA, D. C. I. Efeitos da atividade física na percepção de bem estar de idosas que residem sozinhas e acompanhadas. UNOPAR Científica, Ciências Biológicas e da Saúde, Londrina, PR, v. 7, n. 1, p. 13-20, out. 2005.

ROSENHALL, U. L. F. et al. The two faces of presbyacusis: hearing impairment and psychosocial consequences. Internacional Journal Audiology, v. 41, n. 12, p. 125-135, 2002.

RUSSO, I. C. P. Intervenção audiológica no idoso. In: FERREIRA, L. P., BEFI-LOPES,
D. M.; LIMONGI, S. C. O. (Org.). Tratado de fonoaudiologia. São Paulo: Roca, 2004.

RUSSO, Ieda. Distúrbios da audição: a presbiacusia. In: RUSSO, Ieda (Org.). Intervenção fonoaudiológica na terceira idade. Rio de Janeiro: Revinter, 1999. p. 51-82.

RUSSO, I. C. P.; ALMEIDA, K.; FREIRE, K. M. Seleção e adaptação de prótese auditiva para o idoso. In: ALMEIDA, K.; IORIO, M. C. M. (Org.). Próteses auditivas: fundamentos e aplicações clínicas. São Paulo: Lovise, 2003. p. 385-407.

SASSAKI, R. K. Inclusão: construindo uma sociedade para todos. 7. ed. Rio de Janeiro: WVA, 1997.

SAWAIA, B. As artimanhas da exclusão: análise psicossocial e ética da desigualdade social. Petrópolis, RJ: Vozes, 1999.

SIGNORINI, T. L. B. A deficiência auditiva do idoso e sua implicação na comunicação. 1989. Dissertação (Mestrado em Fonoaudiologia) - Pontifícia Universidade Católica de São Paulo, São Paulo.

TESCH-RÖMER, C. Psychological effects of hearing aid use in older adults. Journal of Gerontology: Psychological Sciences, United States, v. 52b, n. 3, p. 127-138, 1997.

WERNECK, C. Ninguém mais vai ser bonzinho na sociedade inclusiva. Rio de Janeiro: WVA, 1997.

\section{Sobre as autoras:}

Regiane Bergamo Gomes da Silva: Graduação em Fonoaudiologia pela Universidade do Sagrado Coração (USC), Bauru, SP (1994). Especialização em Audiologia Clínica. Mestre em Psicologia, Área de Concentração: Psicologia da Saúde pela Universidade Católica Dom Bosco (UCDB), Campo Grande, MS. Coordenadora do Setor SUS - UCDB. E-mail: regianebergamo@gmail.com

Luciane Pinho de Almeida: Pró-Reitora de Extensão e Assuntos Comunitários e professora no Programa Stricto Sensu em Psicologia da Universidade Católica Dom Bosco (UCDB). Mestrado e doutorado em Serviço Social pela Universidade Estadual Paulista Júlio de Mesquita Filho UNESP). E-mail: luciane@ucdb.br 